This item was submitted to Loughborough's Research Repository by the author.

Items in Figshare are protected by copyright, with all rights reserved, unless otherwise indicated.

\title{
Perinaphthenone phototransformation in a model of leaf epicuticular waxes
}

PLEASE CITE THE PUBLISHED VERSION

http://dx.doi.org/10.1016/j.jphotobiol.2013.10.009

\section{PUBLISHER}

(c) Elsevier

VERSION

AM (Accepted Manuscript)

\section{PUBLISHER STATEMENT}

This work is made available according to the conditions of the Creative Commons Attribution-NonCommercialNoDerivatives 4.0 International (CC BY-NC-ND 4.0) licence. Full details of this licence are available at: https://creativecommons.org/licenses/by-nc-nd/4.0/

\section{LICENCE}

CC BY-NC-ND 4.0

\section{REPOSITORY RECORD}

Trivella, Aurelien S., Shirin Monadjemi, David R. Worrall, lain Kirkpatrick, Emmanuel Arzoumanian, and Claire Richard. 2019. "Perinaphthenone Phototransformation in a Model of Leaf Epicuticular Waxes". figshare. https://hdl.handle.net/2134/18469. 


\section{Perinaphthenone phototransformation in a model of}

\section{2 leaf epicuticular waxes}

3 Aurélien S. Trivella ${ }^{1}$, Shirin Monadjemi ${ }^{1}$, David R. Worrall ${ }^{2}$, Iain Kirkpatrick ${ }^{2}$, Emmanuel

4 Arzoumanian $^{3}$, Claire Richard*,1,4

$5 \quad{ }^{1}$ Clermont Université, Université Blaise Pascal, Institut de Chimie de Clermont-Ferrand (ICCF),

6 BP 10448, 63000 Clermont-Ferrand, France.

$7 \quad$ 2Department of Chemistry, Loughborough University, Loughborough, Leicestershire LE11 3TU

8 UK.

$9 \quad{ }^{3}$ Laboratoire des IMRCP, UMR CNRS 5623, Université Toulouse III (Paul Sabatier, UPS),

1031062 Toulouse Cedex 9, France.

$11 \quad{ }^{4}$ CNRS, UMR 6296, ICCF, 63171 Aubière, France.

12

14 Graphical abstract

15

16

17

18

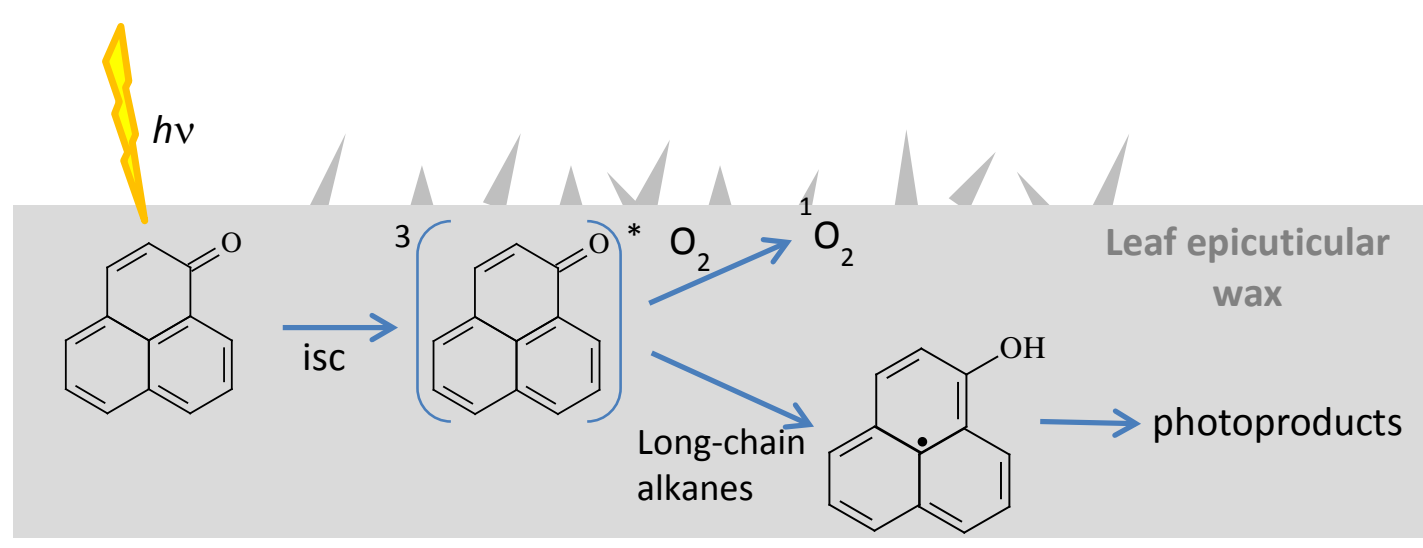


ABSTRACT

20 Perinaphthenone ( $1 H$-phenalen-1-one, PN) is a reference photosensitizer producing singlet

21 oxygen with a quantum yield close to one in a large variety of solvents. It is also the basic

22 structure of a class of phototoxic phytoalexins. In this work, the PN photoreactivity was studied

23 for the first time in a paraffinic wax, used as model of leaf epicuticular waxes. The PN

24 photodegradation was monitored by UV-Vis spectroscopy. The triplet excited state, singlet

25 oxygen and the hydroxyperinaphthenyl radical were detected by diffuse reflectance laser flash

26 photolysis, near infrared phosphorescence and by EPR spectroscopy, respectively. The PN

27 phototransformation was found to be five-fold faster in the wax than in $n$-heptane under steady-

28 state irradiation. The hydroxyperinaphthenyl radical formation was observed in aerated irradiated

29 paraffin wax while in $n$-heptane solution the radical was observed only in the absence of oxygen.

30 These results show that under continuous irradiation, $\mathrm{PN}$ is much more easily phototransformed

31 in a solid environment than in solution. Several photoproducts were identified, in particular

32 phenalanone, PN dimers, and oxidized PN-alkanes adducts. Finally, when pyrethrum extract is

33 added into the wax, the radical concentration was increased by a factor of 2.4. Such

34 photochemical reactions may occur when systemic pesticides enter the plant cuticle.

36 KEYWORDS. Perinaphthenone; photosensitizer; singlet oxygen; phototransformation;

37 epicuticular wax; phytoalexin; hydroxyperinaphthenyl radical; pesticide; pyrethrum extract. 


\section{Introduction}

39 Plants synthesize phytoalexin substances for microbial and often oxidative protection (1-3).

40 These toxins are produced de novo into the leaf cells (4) and have been identified from higher

41 plant tissues into the upper epidermis and in the leaf epicuticular waxes (5-7). Some phytoalexins

42 are phototoxic due to their ability to produce singlet oxygen under solar irradiation (8-10). Many

43 of these natural products are based on the perinaphthenone (1H-phenalen-1-one, PN) skeleton

44 and have been isolated from plants and fungi (11-12). Therefore, the photochemical reaction

45 mechanisms of PN are similar to those of some phytoalexins. PN is used as a reference

46 photosensitizer in photochemistry and photobiology (13). The singlet oxygen production

47 quantum yield of this molecule is close to one over a large solvent range (13-16). Nonetheless, in

48 hydrogen donating solvents, PN can be photodegraded (16-17).

49 The plant leaf epicuticular waxes are mainly composed of long chain alkanes and of other

50 compounds such as esters, ketones and alcohols $(18,19)$. Some of them are hydrogen donors. In

51 this study paraffin wax films are used as a model of the leaf epicuticular waxes. Previous studies

52 were performed with this model at the wax surface (20-22). This model allows a first approach

53 of the photochemical processes occurring in the waxes of a broad variety of plants. Indeed,

54 paraffin wax is a weak hydrogen donating medium but PN phototransformation is expected

55 because of the degradation observed in N,N'-dimethylacetamide and 1,4-dioxane (16). In fact, in

56 these media the competition between singlet oxygen production and PN transformation is not

57 trivial.

58 The ability of phytoalexin to act as a singlet oxygen sensitizer and more generally the

59 photochemistry of phytoalexins can be inconvenient for crop treatments (23, 24). Indeed, some

60 pesticides are oxidized by singlet oxygen $(25,26)$ and these reactions could occur at the leaf 
61 surface and within the leaf epicuticular waxes. Moreover, to our knowledge, no study has been

62 performed on the possible interaction between the PN triplet excited state and pesticides

63 absorbed by plants (systemic pesticides) which enter the cuticle. Under these conditions,

64 pesticide molecules are expected to be in the close environment of phytoalexins that could

65 induce their degradation.

66 For the first time, PN photochemistry is studied in a model of leaf epicuticular waxes. The goal

67 of this study is to give a first approach of the PN photoreactivity in a solid medium composed of

68 long-chain alkanes and to evaluate the competition between singlet oxygen production and

69 phototransformation. Additionally, identification of photoproducts was performed. Finally,

70 pyrethrum extract, a natural pesticide, was added to the paraffin wax film containing PN to

71 obtain evidence of an interaction between the PN triplet excited state and this pesticide.

\section{2. Materials and methods}

$74 \quad$ 2.1. Chemicals

75 Perinaphthenone (97\%), n-heptane (99\%), methanol ( $\geq 99.9 \%$ ), acetonitrile ( $\geq 99.9 \%)$, paraffin 76 wax (mp 53-57 ${ }^{\circ} \mathrm{C}$ ) and silica gel (Davisil grade 634, 100-200 mesh, 60 angstrom, purity $\geq 99 \%$ )

77 were all purchased from Aldrich (Saint-Quentin Fallavier, France). Paraffin wax is a mixture of

78 long-chain alkanes (mainly $\mathrm{C}_{21}-\mathrm{C}_{34}$ ). Pestanal pesticides tembotrione and pyrethrum extract were 79 both purchased from Sigma-Aldrich.

80

812.2 Sample preparations

82 All the samples were prepared in a sodium lamp light room $\left(\lambda_{\text {irr }}=589 \mathrm{~nm}\right)$ to avoid

83 photochemical reactions during handling. Stock solutions of PN in $n$-heptane were prepared at 
84 concentrations ranging from $10^{-3}$ to $10^{-5} \mathrm{M}$ and stored at room temperature. Paraffinic wax films

85 containing PN were prepared as follows: $72 \mathrm{mg}$ of wax and $16.54 \mathrm{mg}$ of PN were mixed and

86 heated at $100^{\circ} \mathrm{C}$ under magnetic stirring to obtain a homogeneous liquid. Subsequently, the

87 mixture was poured on aluminum foil and pressure was applied using a plate to produce the

88 films. The $10^{-3} \mathrm{M}$ PN solid concentration in the paraffin wax films was calculated based on a

89 wax density of $0.77 \mathrm{~g} \mathrm{~mL}^{-1}$. Less concentrated films were obtained by dilution with pure

90 paraffinic wax. In all cases, films containing PN were rinsed with acetonitrile to remove any PN

91 molecules remaining at the film surface. For UV-Visible spectroscopy, PN was mixed with

92 cellulose at a 1/100 ratio in weight. For laser flash photolysis paraffin wax films containing PN

93 were directly used without further modification. Silica gel samples containing adsorbed PN were

94 used to monitor the triplet decay in the absence of oxygen. They were prepared as follows: $2 \mathrm{~g}$ of

95 silica gel were dried by heating at $120^{\circ} \mathrm{C}$ under vacuum for 2 hours to a pressure of $5 \times 10^{-5}$ mbar.

96 Then, a PN solution at a concentration of $100 \mu \mathrm{M}$ in methanol was added to the silica. The

97 solvent was evaporated under vacuum at room temperature. Then, the sample was maintained

98 under vacuum for 4 hours to ensure removal of trace methanol, water, and air. Finally, the

99 samples were sealed under vacuum in a quartz cuvette. For EPR analyses the liquid mixture

100 containing wax and PN was directly poured inside pyrex tubes. Pesticides were added to the hot

101 liquid wax-PN mixture under magnetic stirring at amounts calculated to obtain a final

102 concentration of $10^{-3} \mathrm{M}$ for tembotrione and $4.3 \mu \mathrm{L} \mathrm{ml}^{-1}$ for the pyrethrum extract.

103

$104 \quad 2.3 \mathrm{UV}$-Vis spectroscopy

105 Liquid state absorption spectra were recorded using a Cary 3 UV-Visible spectrometer (Varian).

106 Baselines and spectra were recorded at room temperature in the $800-250 \mathrm{~nm}$ spectral range with 
107 a 1-nm resolution and a $600 \mathrm{~nm} \cdot \mathrm{min}^{-1}$ scan rate. Solid state UV-Visible spectra were recorded 108 using a DRA-CA-30I integrating sphere accessory (Varian) and a $\mathrm{BaSO}_{4}$ reflectance standard 109 (Spectralon). PN mixed with cellulose was poured into a circular quartz cell of 1-cm thickness 110 and then the cell was placed in the diffuse reflectance port of the sphere accessory. UV-Vis 111 absorption spectra of paraffin wax films containing PN were recorded by positioning the film in

112 the transmission port of the sphere accessory. The signal intensity measured in percentage of 113 transmittance was converted to absorbance from equation (1):

$$
A(P N)=\log \left(\frac{I_{t}(P a)}{I_{t}(P N+P a)}\right)
$$

115 where $\mathrm{A}(\mathrm{PN})$ is the $\mathrm{PN}$ absorbance, $\mathrm{I}_{t}(\mathrm{~Pa})$ and $\mathrm{I}_{t}(\mathrm{~Pa}+\mathrm{PN})$ are the transmitted light through the 116 pure paraffin and paraffin containing PN samples, respectively. For PN dissolved in $n$-heptane, 117 the molar absorption coefficient was calculated from UV-Vis absorption spectra of $10^{-4}, 2 \times 10^{-5}$, 118 and $10^{-5} \mathrm{M}$ solutions. In the case of paraffin wax containing $\mathrm{PN}$, the molar absorption coefficient 119 was calculated from transmission spectra of four different films containing $10^{-4} \mathrm{M}$ of PN. The 120 film thickness was measured using a MI20 Micrometer (Messmer Instrument Ltd). The average

121 film thickness was $500 \pm 100 \mu \mathrm{m}$. Molar absorption coefficient calculations of paraffin wax 122 films containing PN were based on the Beer-Lambert law (27).

$124 \quad 2.4$ Photodegradation quantum yield and rate constants measurements

125 All the samples were irradiated at $366 \mathrm{~nm}$ (room temperature) using a mercury lamp (Oriel, 200 $126 \mathrm{~W})$ equipped with a monochromator (Photomax). The average photon fluence rate $\left(E_{\mathrm{p}, \mathrm{o}}=\right.$ $1272.0 \times 10^{15} \mathrm{~cm}^{-2} \mathrm{~s}^{-1}$ ) was measured using a QE65000 UV-Visible spectrometer (Ocean Optics). Air128 saturated solutions were irradiated in a cubic quartz cell of 1-mm pathlength. The decay of PN 129 was monitored by UV-visible spectroscopy. The paraffin wax films containing PN were placed 
130 on a sample holder that allowed reproducible positioning of the sample for irradiation and UV-

131 Visible analysis. The $\sim 500 \mu \mathrm{m}$ thickness films were irradiated under the same conditions as the

132 solutions. Irradiation experiments were carried out in triplicate. Quantum yields of PN

133 photodegradation $\left(\Phi_{\mathrm{deg}}\right)$ were determined in air-saturated $n$-heptane and paraffin wax. The $\Phi_{\mathrm{deg}}$

134 values were calculated from equation 2:

135

$$
\Phi_{\text {deg }}=\frac{\Delta[\mathrm{PN}]}{\mathrm{P}_{\mathrm{a}} \cdot \Delta \mathrm{t}} \cdot 10^{-3} \cdot \mathrm{N}_{\mathrm{A}} \cdot \ell
$$

136 where $\Phi_{\operatorname{deg}}$ is the PN photodegradation quantum yield, $\Delta[\mathrm{PN}]\left(\mathrm{mol} \mathrm{L}^{-1}\right)$ is the loss of PN

137 concentration after irradiation, $\mathrm{P}_{\mathrm{a}}\left(\mathrm{cm}^{-2} \mathrm{~s}^{-1}\right)$ is the photon fluence rate absorbed by the sample, $\Delta \mathrm{t}$

138 (s) is the irradiation duration, $\mathrm{N}_{\mathrm{A}}$ is the Avogadro number, and $\ell(\mathrm{cm})$ is the sample pathlength.

139 Calculation of $\Phi_{\text {deg }}$ was based on a concentration loss of not more than $10 \%$ of the initial

140 concentration, in order to avoid underestimation that could be due to overlapping absorption of

141 PN and photoproducts.

$143 \quad 2.5$ LC-MS analyses

144 The MS system employed consisted of an LC/QTOF equipped with an orthogonal geometry Z-

145 spray ion source (Waters/Micromass, Manchester, UK). For UV detection, a photodiode array

146 detector Waters Alliance 2695 system was used. A volume of $40 \mu \mathrm{L}$ was injected on a reversed-

147 phase column (Kinetex, Phenomenex, C18, $2.6 \mu \mathrm{m}, 100 \mathrm{~mm}$ x $2.1 \mathrm{~mm}$ ). A flow rate of 0.2

$148 \mathrm{~mL} \mathrm{~min}{ }^{-1}$ was set. The binary solvent system used was composed of acetonitrile (ACN) and

149 milli-Q water. The gradient elution started with 5\% ACN and reached 95\% ACN in 15 min

150 linearly. These conditions were kept during $25 \mathrm{~min}$. The desolvation chamber and ion source

151 block temperatures were set at $180^{\circ} \mathrm{C}$ and $100^{\circ} \mathrm{C}$, respectively. $\mathrm{N}_{2}$ was used as the nebulizer gas

$152\left(35 \mathrm{~L} \mathrm{~h}^{-1}\right)$ and the desolvation gas $\left(250 \mathrm{~L} \mathrm{~h}^{-1}\right)$. The electrospray interface was operating in 
153 positive and negative ion modes. The capillary voltage was $3000 \mathrm{~V}$; the sample cone and the

154 extraction cone were set at $35 \mathrm{~V}$ and $1 \mathrm{~V}$ respectively. Data were acquired over the $\mathrm{m} / \mathrm{z}$ 90-1000

155 range at a scan rate of one second per spectrum. The data recorded were processed with

156 MassLynx (version 4.1). PN irradiated 15 hours in $n$-heptane and 30 minutes in paraffin wax

157 film at $366 \mathrm{~nm}$ were analyzed. For the $n$-heptane sample the solvent was evaporated at room

158 temperature and the obtained powder was dissolved in ACN. For the paraffinic wax sample, PN

159 and its photoproducts were extracted by dissolving the wax in $n$-heptane and by adding ACN in a

$1601: 1(\mathrm{v}: \mathrm{v})$ ratio.

161

$162 \quad 2.6$ Laser flash photolysis

163 Transient absorption experiments were carried out on two different devices. Photolysis of 164 paraffin wax films containing PN was conducted at the Institut de Chimie de Clermont-Ferrand 165 (Clermont-Ferrand, France). The apparatus consists of a laser flash photolysis spectrometer from 166 Applied Photophysics (LKS.60) equipped with a Quanta Ray GCR 130-01 Nd:YAG laser ( $\lambda=$ $167355 \mathrm{~nm}$, pulse width of 5-7 ns). The device has been previously described (28). Diffuse 168 reflectance mode was used for the paraffin wax film sample studies. Time resolved absorption 169 spectra were available in the nanosecond to second timescales. Experiments conducted on the 170 paraffin wax films containing PN were made by measuring the reflectance change $(\Delta \mathrm{R}$, equation 1713 ) from the transient species signal intensity:

$$
\Delta \mathrm{R}=\frac{R_{0}-R_{t}}{R_{0}}
$$

173 where $\Delta \mathrm{R}$ is the transient species reflectance change, $\mathrm{R}_{0}$ and $\mathrm{R}_{\mathrm{t}}$ correspond to the diffusely

174 reflected light before exposure to the laser pulse and at time $t$ after excitation, respectively. 
175 Laser flash photolysis experiments on PN adsorbed on silica gel were performed at 176 Loughborough University (Loughborough, UK). The nanosecond diffuse reflectance laser flash 177 photolysis apparatus has been previously described $(29,30)$ and excitation of the samples was 178 performed with the third harmonic (355 nm, pulse width of $5 \mathrm{ns)}$ of a Surelite I Nd:YAG laser 179 (Continuum). The laser pulse energy at maximum output was $100 \mathrm{~mJ}$ per pulse, with pulse 180 energy being controlled by varying the Q-switch delay. Diffusely reflected analyzing light from a $181300 \mathrm{~W}$ xenon arc lamp (Oriel) was collected and focused onto the entrance slit of an $f / 3.4$ 182 grating monochromator (Applied Photophysics) and detected with a side-on photomultiplier tube 183 (Hamamatsu R928). Signals were captured using an LT364 Waverunner digitizing oscilloscope 184 (LeCroy). Rate constants for deactivation of transient species in paraffin wax were calculated 185 using a first order deactivation kinetics law (4):

$$
y=\mathrm{A}_{1} \cdot e^{-k t}+y_{0}
$$

187 where $\mathrm{y}$ and $\mathrm{y}_{0}$ are the transient species absorbance after and before the laser pulse, respectively.

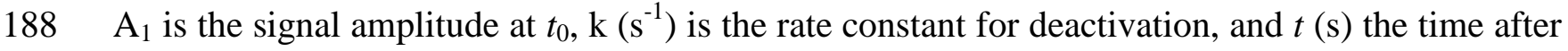
189 the laser pulse. Since transient decay data obtained from systems in heterogeneous media rarely 190 exhibit mono-exponential behaviour, decay of the phenalenone excited triplet state on silica gel 191 was analysed using the dispersive kinetic model of Albery et al. which treats the data as being a $192 \log$ Gaussian distribution of rate constants (31), according to equation (5).

$$
\frac{\mathrm{C}}{\mathrm{C}_{0}}=\frac{\int_{-\infty}^{\infty} \exp \left(-t^{2}\right) \exp [-\bar{k} t \exp (\gamma t)] d t}{\int_{-\infty}^{\infty} \exp \left(-t^{2}\right) d t}
$$

194 where $C$ and $C_{0}$ represent transient concentrations (or $\Delta \mathrm{R}$ and $\Delta \mathrm{R}_{0}$ at low sample loadings) at 195 times $t$ and $t_{0}$ after the laser pulse. The width of the distribution is given by $\gamma$ and $\bar{k}$ is the mean 
196 rate constant. Fitting was carried out using a modified sequential Simplex algorithm such that a

197 global minimum in the reduced $\chi^{2}$ parameter space was obtained. This procedure has been

198 described previously in reference (32). A comparison of the suitability of this fitting method and

199 a mono-exponential decay has been discussed previously in reference (33).

\subsection{EPR spectroscopy}

202 EPR spectra were recorded on a Bruker EMX EPR spectrometer interfaced to a computer with 203 WinEPR Acquisition system software. The spectrometer had the following general settings: 204 center field $349.583 \mathrm{mT}$, sweep field $10 \mathrm{mT}$, frequency $9.81 \mathrm{GHz}$, power $20.12 \mathrm{~mW}$, sweep time $20583.9 \mathrm{~s}$, time constant $5.12 \mathrm{~ms}$, modulation frequency $100 \mathrm{kHz}$, gain $3.17 \times 10^{5}$ and modulation 206 width $0.05 \mathrm{mT}$. Each EPR spectrum was recorded at ambient temperature and 10 scans were 207 accumulated. The signal acquisition was performed during sample irradiation from a $1000 \mathrm{~W}$ 208 Xe-Hg arc lamp (Schoeffel Instruments). EPR spectra obtained from paraffin wax films 209 containing PN were smoothed with a 9 point adjacent average. EPR analyses of PN dissolved in

$210 n$-heptane at a concentration of $10^{-3} \mathrm{M}$ in air saturated solution and deoxygenated solution (argon 211 purged for $15 \mathrm{~min}$ ) were performed. The kinetics of the formation of the PN radical were 212 followed during PN irradiation by measuring the signal intensity centered at $3491.42 \mathrm{G}$ as a 213 function of time.

2152.8 Singlet oxygen phosphorescence measurements

216 The equipment for the continuous monochromatic excitation of the sensitizer for the 217 measurements of the ${ }^{1} \mathrm{O}_{2}$ phosphorescence at $1270 \mathrm{~nm}$ has been previously described in detail $218(14,34,35)$. The paraffin wax film containing PN at a concentration of $10^{-3} \mathrm{M}$ was placed on a 
219 sample holder oriented at $45^{\circ}$ relative to a $1000 \mathrm{~W}$ Xe-Hg arc lamp, coupled to a monochromator

220 (6 nm bandwidth) adjusted to $367 \mathrm{~nm}$. A cooled $\left(-80^{\circ} \mathrm{C}\right)$ NIR photomultiplier (Hamamatsu) was

221 used as a ${ }^{1} \mathrm{O}_{2}$ detector. The ${ }^{1} \mathrm{O}_{2}$ luminescence was collected with a mirror, chopped and, after 222 passing through a focusing lens, a cut-off filter $(1000 \mathrm{~nm})$ and an interference filter $(1271 \mathrm{~nm})$, 223 was measured at $90^{\circ}$ with respect to the incident beam.

224

225 3. Results and discussion

$2263.1 \mathrm{UV}-\mathrm{Vis}$ absorption spectra of perinaphthenone in solution and in solid media

227 UV-Vis absorption spectroscopy was used to determine whether PN is molecularly dispersed in

228 the paraffin wax films or aggregated. In fact, phototoxic phytoalexins present in the plant leafs

229 and irradiated by sunlight are not aggregated. Photochemistry of non-aggregated and aggregated

230 molecules can be different because of the possibility of intermolecular deactivations in the latter

231 case. As a first step we checked that our model is relevant for the studied system. The molecular

232 aggregation can be clearly identified by UV-Vis absorption spectroscopy. In fact, the increase of

233 intermolecular interactions leads to a shift of the absorption maxima and a broadening of the

234 bands. Figure 1 displays the PN UV-Vis spectra recorded in different media; $n$-heptane, paraffin

235 wax, and cellulose.

236 In $n$-heptane, where PN is completely solubilized at a concentration of $10^{-4} \mathrm{M}$, the absorption

237 maximum is found at $353 \mathrm{~nm}$ with a band full width at half maximum (FWHM) of $57 \mathrm{~nm}$

238 (Figure 1.a). When PN is mixed with cellulose, a broadening of the UV-Vis band is observed 239 compared to that in solution (Figure 1.b). This phenomenon is due to the formation of small PN

240 crystals. The absorption band is broad and centered at $395 \mathrm{~nm}$, and two distinct shoulders are 241 observed at 363 and $465 \mathrm{~nm}$ with a band FWHM of $101 \mathrm{~nm}$ (Figure 1.b). UV-Vis spectrum of 
242 paraffin wax film containing PN shows an absorption maximum at $354 \mathrm{~nm}$ and a band FWHM of

$24363 \mathrm{~nm}$. Molar absorption coefficients were calculated for PN dissolved in $n$-heptane and in

244 paraffin wax. The obtained values are of $11500 \pm 600 \mathrm{M}^{-1} \cdot \mathrm{cm}^{-1}$ and $16100 \pm 1600 \% \mathrm{M}^{-1} \cdot \mathrm{cm}^{-1}$ at

245353 and $354 \mathrm{~nm}$, respectively.

246 Comparison of the UV-Vis absorption spectra of PN dissolved in $n$-heptane and in paraffin wax

247 shows small differences. The maxima are separated by only $1 \mathrm{~nm}$ and the band FWHM (full

248 width at half maximum) is $10 \%$ smaller in $n$-heptane. In contrast, the UV-Vis spectra of PN in

249 paraffin wax and cellulose display strong differences. Their maxima are separated by $41 \mathrm{~nm}$ and

250 the band FWHM is 60\% larger in cellulose. The PN crystals are thus well dissolved in the

251 paraffin wax and no aggregation occurs during film preparations. Taking into account these

252 results, we can conclude that paraffin wax films containing PN can be used as a model system

253 for the photochemical behavior of phytoalexins present in leaf epicuticular waxes. Another

254 important parameter is the molar absorption coefficient. It is $30 \%$ larger in the wax film

255 compared to solution. Such differences in the absorptivity between the liquid and the solid phase

256 have been already reported for other molecules $(36,37)$. At very low PN concentration, which is

257 close to real conditions, this would lead to an amount of absorbed light about $30 \%$ higher than

258 that measured in the liquid alkane.

259

2603.2 Compared perinaphthenone phototransformation in n-heptane and paraffin wax film

261 In this study, $n$-heptane is used as a reference solvent for the comparison of the PN

262 photochemical behavior between liquid and solid paraffinic media. Figure 2 shows the UV-Vis

263 absorption spectra evolution under irradiation at $366 \mathrm{~nm}$ of PN dissolved in $n$-heptane and in

264 paraffin wax at $10^{-4} \mathrm{M}$. In $n$-heptane (Figure 2.a) the PN absorption band decreases by $12 \%$ after 
$2651 \mathrm{~h}$. Simultaneously, a new band is observed at wavelengths lower than $325 \mathrm{~nm}$, indicative of 266 photoproducts formation.

267 In paraffin wax film (Figure 2.b) PN is photodegraded faster by $42 \%$ after $30 \mathrm{~min}$. Moreover, in 268 paraffin wax film, absorbance increases above $420 \mathrm{~nm}$ (Figure 2.b), in addition to the absorption 269 bands below $325 \mathrm{~nm}$. The absorbance above $420 \mathrm{~nm}$ is weaker that than at shorter wavelengths 270 and results in a yellow coloration of the paraffin wax. The absence of photoproduct bands above $271420 \mathrm{~nm}$ in $n$-heptane can be explained by the small amount formed relative to the wax film. PN 272 quantum yields of photodegradation ( $\Phi_{\text {deg }}$ ) were calculated from the UV-Vis spectra. Values of $273 \Phi_{\text {deg }}$ are $3.5( \pm 0.4) \times 10^{-4}$ and of $1.7( \pm 0.4) \times 10^{-3}$ in $n$-heptane and wax film, respectively. Therefore, 274 the PN degradation is five-fold more efficient in paraffin wax containing PN than in n-heptane. 275 LC-MS analyses were performed to determine the nature of photoproducts. In deoxygenated n276 heptane, where PN is readily photodegraded and photoproducts accumulate, several chemicals 277 were identified (Figure 3). We successfully detected in positive mode phenalanone (PL, $278 \mathrm{~m} / \mathrm{z}=183$ ) corresponding to $[\mathrm{PN}+2 \mathrm{H}+\mathrm{H}]^{+}$as well as several adducts. The adduct with $\mathrm{m} / \mathrm{z}=361$ 279 corresponds to $[2 \mathrm{PN}+\mathrm{H}]^{+}$; it should be formed by the addition of the hydroxyperinaphthenyl 280 radical (HPN) to $\mathrm{PN}$ followed by a $\mathrm{H}$ elimination. The adduct with $\mathrm{m} / \mathrm{z}=363$ corresponds to $281[\mathrm{PN}+\mathrm{PN}+2 \mathrm{H}+\mathrm{H}]^{+}$, i.e. to the addition of two HPN radicals. Photoproducts with $\mathrm{m} / \mathrm{z}=279$ 282 correspond to [PN+H+C$\left.+\mathrm{C}_{73}+\mathrm{H}\right]^{+}$and thus to the addition of the HPN radical to a radical 283 deriving from $n$-heptane. For all these coupling products, several isomers were detected. By MS², 284 all lost CO confirming the presence of at least a carbonyl function on each. In addition, none 285 were detectable in negative mode ruling out the presence of $\mathrm{OH}$ functions. On the basis that the 286 molar absorption coefficients are approximately the same for each photoproduct, the major ones 287 are the PN-n-heptane adducts. When PN was irradiated in air-equilibrated paraffin wax film, LC- 
MS positive mode allowed to detect oxidized PN ([PN+O+H $\left.]^{+}, \mathrm{m} / \mathrm{z}=197\right), \mathrm{PL}(\mathrm{m} / \mathrm{z}=183)$, and

289 adduct $[2 \mathrm{PN}+\mathrm{H}]^{+}(\mathrm{m} / \mathrm{z}=361)$. From the LC-MS negative mode analysis $\left[\mathrm{PN}+\mathrm{H}+\mathrm{C}_{\mathrm{n}} \mathrm{H}_{2 \mathrm{n}-2}+\mathrm{O}_{\mathrm{y}}\right]^{-}$

290 adducts were identified for $n=5,7$, and 9 , and $y=1$ or 2 (see supplementary information).

$292 \quad 3.3$ Triplet state formation

293 The PN triplet excited state $\left({ }^{3} \mathrm{PN}^{*}\right)$ has been previously observed in many solvents (38), its UV-

294 Vis absorption spectrum displaying a maximum at around $500 \mathrm{~nm}$. In paraffin wax film, the UV-

295 Vis diffuse reflectance spectrum of ${ }^{3} \mathrm{PN}^{*}$ has been recorded after pulsed laser excitation at 355

$296 \mathrm{~nm}$ (Figure 4.a). The spectrum displays a maximum at $490 \mathrm{~nm}$ with a transient species decay rate

297 constant of $1.7 \times 10^{5} \mathrm{~s}^{-1}$ (triplet lifetime of $5.9 \mu \mathrm{s}$ ) in the air-equilibrated conditions. Making the

298 hypothesis that the oxygen concentration is the same in the wax as in $n$-heptane $\left(2.8 \times 10^{-3} \mathrm{M}, 39\right)$,

299 one gets $k_{\mathrm{O} 2}=6.1 \times 10^{7} \mathrm{M}^{-1} \mathrm{~s}^{-1}$ (scheme 1 ), which is 46 times lower than in $n$-heptane $\left(2.6 \times 10^{9} \mathrm{M}^{-}\right.$

$300{ }^{1} \mathrm{~s}^{-1}$ ). This latter value was deduced from the ${ }^{3} \mathrm{PN}^{*}$ decay rate constants measured in argon-

301 saturated $\left(6.0 \times 10^{4} \mathrm{~s}^{-1}\right)$, air-saturated $\left(7.8 \times 10^{6} \mathrm{~s}^{-1}\right)$, and oxygen-saturated $\left(3.6 \times 10^{7} \mathrm{~s}^{-1}\right) n$-heptane

302 solutions. This significant difference on $k_{\mathrm{O} 2}$ is explained by the lower mobility of oxygen in a

303 solid matrix compared to a liquid alkane. In solid polystyrene for instance, the diffusion

304 controlled rate constant is $\sim 2 \times 10^{8} \mathrm{M}^{-1} \mathrm{~s}^{-1}$ and the rate constant for oxygen quenching of triplet

305 state sensitizers was evaluated as to be $\sim 1.5 \times 10^{7} \mathrm{M}^{-1} \mathrm{~s}^{-1}(40)$. Experiments in the absence of

306 oxygen were conducted using silica gel samples prepared under high vacuum. A rate constant of

$307174 \mathrm{~s}^{-1}$ (5.7 ms) was measured for the transient decay under vacuum (Figure 4.b). When the

308 evacuated sample was exposed to air, the PN transient species was completely quenched on these

309 timescales, confirming the attribution of the transient to ${ }^{3} \mathrm{PN}^{*}$. The formation of radical species

310 in the wax is likely, as evidenced by the observed PN degradation. Flors et al. have observed 
311 their formation in organic solvents (41). In this system, spectral overlap of the triplet state and

312 radical make direct observation of the latter difficult.

3143.4 Singlet oxygen production

315 The formation of singlet oxygen was monitored by near infrared phosphorescence (Figure 5). A

316 strong signal was observed and continuous irradiation of a paraffin wax film containing PN at

$317367 \mathrm{~nm}$ for 55 minutes leads to a 50\% signal loss. Two steps are observed during the decrease of

318 the signal. In fact, the signal loss is $35 \%$ in the first 20 minutes of irradiation while it is only $15 \%$

319 during the following 35 minutes. Considering that the quantum yield of singlet oxygen

320 production by PN is close to one in most media and that no singlet oxygen acceptor or quencher

321 is present in the paraffin wax, the ${ }^{1} \mathrm{O}_{2}$ concentration should be stable under irradiation.

322 Therefore, the ${ }^{1} \mathrm{O}_{2}$ signal loss provides further experimental evidence of the PN

323 photodegradation. Another possible reason for this ${ }^{1} \mathrm{O}_{2}$ signal loss may be the decrease of oxygen

324 concentration in the film due to the formation of oxidation photoproducts.

325

3263.5 Hydroxyperinaphthenyl radical formation

327 The formation of the hydroxyperinaphthenyl radical (HPN*) was previously observed in

328 deoxygenated 2-propanol by Rabold et al. (17). We monitored this radical formation in $n$ -

329 heptane and paraffin wax under irradiation. In air saturated $n$-heptane solution, no EPR signal

330 was observed during PN irradiation, in line with the very low $\Phi_{\operatorname{deg}}$ in this solvent. In

331 deoxygenated $n$-heptane, the HPN` EPR signal was observed (Figure 6.a). The spectrum consists

332 of six quadruplets separated by $6.19 \mathrm{G}$. Within each quadruplet, bands are separated by $1.74 \mathrm{G}$.

333 The intensity ratios within the quadruplets are close to 1:3:3:1 while the ratios between the six 
334 quadruplets are of 1:4.5:8.8:8.8:4.5:1. Interestingly, in irradiated air-equilibrated paraffin wax we

335 observed an EPR signal showing the same coupling constants as those measured in $n$-heptane,

336 only the intensity ratios were changed due to the sample anisotropy (Figure 6b). Thus, the HPN

337 radical is formed in both deoxygenated $n$-heptane and in air equilibrated paraffin wax.

338 Detection of the HPN• radical in $n$-heptane was possible because oxygen was partly removed.

339 Indeed, the efficient quenching of ${ }^{3} \mathrm{PN}^{*}$ by oxygen (Reaction (6)) does not compete with its

340 reaction with the solvent (hydrogen abstraction, Reaction (7)). The PN radical is likewise

341 observed in paraffin wax in aerated conditions. In fact, this result is consistent with PN

342 irradiation kinetics monitored by UV-Vis spectroscopy (Figure 2) and singlet oxygen near

343 infrared phosphorescence experiments (Figure 5) where PN is degraded in the paraffin wax

344 under air.

$$
\begin{array}{ll}
{ }^{3} \mathrm{PN}^{*}+{ }^{3} \mathrm{O}_{2} \rightarrow \mathrm{PN}+{ }^{1} \mathrm{O}_{2} & k_{\mathrm{O} 2} \\
{ }^{3} \mathrm{PN}^{*}+\mathrm{RH} \rightarrow \mathrm{HPN}+\mathrm{R}^{\bullet} & k_{\mathrm{RH}}
\end{array}
$$

348 3.6 Comparison of reactivity in $n$-heptane and paraffinic wax

349 We have shown that PN exhibits a higher photodegradability in paraffinic wax than in $n$-heptane.

350 The mechanism given in Scheme 1 established using our experimental data may explain these

351 differences. Following the electronic excitation of $\mathrm{PN},{ }^{3} \mathrm{PN}^{*}$ is formed from ${ }^{1} \mathrm{PN}^{*}$ by intersystem

352 crossing and the efficiency of this process ( $\left.\Phi_{\text {ISC }}\right)$ should be close to one in liquid as in solid

353 phases $(14,42)$. In the presence of oxygen, ${ }^{3} \mathrm{PN}^{*}$ can either transfer its energy to oxygen or

354 abstract a hydrogen atom from the solvent to yield the hydroxyperinaphthenyl radical $(15,16)$. In

$355 n$-heptane, the former reaction is dominant as the quantum of singlet oxygen production is close

356 to 1. In paraffin wax, the signal obtained could not be quantified, but its intensity strongly 
suggests a high efficiency of singlet oxygen production (Figure 5). Nonetheless, $\Phi_{\text {deg }}$ is 5-fold

358 higher in the wax compared to $n$-heptane. Although the effect on ${ }^{1} \mathrm{O}_{2}$ production could be minor

359 in the first stages of the reaction, the sensitizing properties of PN may be altered significantly in

360 case of extended use. A recent computational study by Segado et al. (42) shows that the lowest

361 energy triplet state of $\mathrm{PN}$ is of $\pi \pi^{*}$ character where singlet oxygen formation is the main

362 photochemical process. However, their study also indicates an equilibrium between this $\pi \pi^{*}$

363 triplet state and a low lying $n \pi^{*}$ triplet state, allowing for hydrogen abstraction to occur.

364 This difference of $\Phi_{\text {deg }}$ between $n$-heptane and wax may be related to differences in the rate

365 constants of the two competing reactions ( $k_{\mathrm{RH}}$ and $\left.k_{\mathrm{O} 2}\right)$. The lower mobility of molecules in the

366 wax suggests lower rate constants. This was demonstrated in the case of $k_{\mathrm{O} 2}$. In the case of $k_{\mathrm{RH}}$,

367 PN is surrounded by solvent molecules and the mobility may have less importance. If we

368 postulate that $k_{\mathrm{RH}}$ is of the same magnitude in the two media, the difference in $\Phi_{\mathrm{deg}}$ values must

369 be assigned to a lower value of $k_{\mathrm{O} 2}$.

370 The detection of the hydroxyperinaphthenyl radical (HPN*) in wax only in spite of the presence

371 of oxygen was a rather surprising result. The stationary concentration of HPN ${ }^{\bullet}$ is given by

372 comparing the rates of production and of decay. Even though the rate of HPN formation is

373 slower in $n$-heptane than in the wax because the scavenging of ${ }^{3} \mathrm{PN}^{*}$ by oxygen is faster, the non-

374 observation of $\mathrm{HPN}^{*}$ in $n$-heptane also indicates that the decay rate and thus the reactivity of

375 HPN• radical is probably higher in n-heptane than in wax. Nevertheless, there is no parallel

376 between the $\Phi_{\operatorname{deg}}$ and the $\mathrm{HPN}^{\bullet}$ stationary concentration increase from n-heptane to wax. This

377 suggests that re-oxidation of HPN`radical occurring as a result of interaction with dissolved 378 oxygen, to regenerate PN, is the dominant pathway. Finally, the identified photoproducts in $n$ - 
379 heptane and paraffin wax film media derive from $\mathrm{HPN}^{\bullet}$ radical which may abstract another $\mathrm{H}$ 380 atom and yield phenalanone, add onto PN or on a second HPN radical to give dimers of PN. The

381 main reaction is the coupling of $\mathrm{HPN}^{\bullet}$ with an oxygenated radical deriving from the solvent.

382 These results show that a reference photosensitizer can be photodegraded in solid media

383 consisting of weak hydrogen donor molecules. By extension, the phototoxic phytoalexins

384 structurally close to PN could be degraded in the leaf epicuticular waxes. Moreover, these leaf

385 waxes include alcohols which are strong hydrogen donors and could increase the degradation

386 efficiency. Another aspect not discussed until now is the impact on pesticides. The pesticide

387 activities could be lowered by the phototoxic phytoalexins reactivity. This is discussed in the last

388 section of the paper.

3903.7 Environmental implication: phytoalexins in the epicuticular waxes could photosensitize 391 pesticide degradation

392 The phototoxic activities of phytoalexins must be taken into account for crop treatments $(23,24)$.

393 In fact, some pesticides are oxidized by singlet oxygen (25, 26). Moreover, we bring evidence of

394 possible reactions between the ${ }^{3} \mathrm{PN}^{*}$ and/or $\mathrm{PN}$ derived radicals with pesticides. In this work, we 395 selected as model compounds tembotrione and pyrethrum extract that can be absorbed by plants 396 and therefore can be found in the phytoalexins close environment. The kinetics of formation of

397 the HPN• radical was monitored by EPR spectroscopy under continuous irradiation of paraffin 398 wax containing PN (Figure 7.a), PN and tembotrione (Figure 7.b), and PN and pyrethrum extract 399 (Figure 7.c). A Xe-Hg arc lamp was used as irradiation source, the lamp emission being filtered 400 by Pyrex tube. The results show that the HPN ${ }^{*}$ concentration was higher in the presence of 
401 pyrethrum extract by a factor of 2.4 while no difference was observed between waxes containing 402 tembotrione and PN alone.

403 These results brought evidence of an interaction between excited PN and the pyrethrum extract

404 while tembotrione showed no apparent effect. At this stage it is not possible to go further in the 405 understanding of the involved mechanisms because of the specific features of each pesticide.

406 However, we could demonstrate the photoreactivity of PN may be modified in the presence of a

407 pesticide. By extension, we can assume that pesticide activities can be modified not only by the

408 singlet oxygen photosensitizing the ability of phytoalexins but also as a result of their

409 photodegradation.

\section{4. Conclusions}

412 In this work, we have studied for the first time the PN photoreactivity in a model of leaf

413 epicuticular waxes. Through this model we have highlighted the potential reactivity of

414 phototoxic phytoalexins absorbing sunlight; especially PN structural analogues. Indeed, even

415 when the estimated PN phototransformation quantum yield is low, PN degradation was observed

416 in paraffin wax films under continuous irradiation. Moreover, alkanes are weak hydrogen

417 donors. A more realistic model of the leaf epicuticular wax would imply addition of alcohols and

418 other functional groups, and an increase of the phototransformation efficiency would be expected

419 under those conditions. Similarly, the phototoxic phytoalexins could be degraded in the leaf

420 epicuticular waxes. The consequence could be a weakening of the plant defense mechanisms

421 against microbial attacks. Evidence of that effect, in the case of paraffin wax film containing PN,

422 was given by the observation of a decrease in singlet oxygen production coupled to the formation

423 of a hydroxyperinaphthenyl radical ( $\left.\mathrm{HPN}^{*}\right)$. Therefore, even if the radical formation is the minor 
424 process, it may alter significantly the sensitizing properties of PN for prolonged use. PN

425 phototransformation in the wax leads to the formation of phenalanone, dimer species and mainly

426 oxidized PN-alkanes adducts. These species are potential singlet oxygen photosensitizers and

427 reductor agents. In $n$-heptane, the fast reaction of $\mathrm{HPN}^{\bullet}$ with ground state oxygen to yield back

$428 \mathrm{PN}$ and the perhydroxyl radical $\left(\mathrm{HO}_{2}{ }^{\circ}\right)$ prevents its detection. Nonetheless, phenalanone, dimer

429 species and PN-alkanes adducts were also identified in deoxygenated solutions as expected.

430 Finally, tembotrione and pyrethrum extract pesticides which can be absorbed by plants were

431 added to the paraffin wax containing PN. The concentration of HPN` was 2.4 times higher in the

432 presence of pyrethrum extract. Transposition of this result to phytoalexins photoreactivity leads

433 to the conclusion that effects on the pesticide activities should be considered not only through

434 singlet oxygen production but also H-atom abstraction.

435

436 ASSOCIATED CONTENT

437 Supporting Information

438 Irradiated PN dissolved in deoxygenated $n$-heptane and air-equilibrated paraffin wax film

439 containing PN samples analyzed by LC-MS positive and negative ionization modes are reported.

440 Decay kinetics of PN triplet excited state in controlled atmospheres are also reported.

\section{AUTHOR INFORMATION}

\section{Corresponding Author}

444 *E-mail: claire.richard@univ-bpclermont.fr; phone: 0033(0)4.73.40.71.42 


\section{Acknowledgements}

448 The authors are thankful to Lawrence Frezet (UBP START team) for his experimental support 449 on EPR analyses. They also express their gratitude to Dr Esther Oliveros (Université Toulouse $450 \quad$ III) for helpful discussions.

451 
453 (1) F. Kurosaki, A. Nishi, Isolation and antimicrobial activity of the phytoalexin 6454 methoxymellein from cultured carrot cells, Phytochem. 22 (1983) 669-672.

455 (2) J. G. Luis, W. Q. Fletcher, F. Echevem, T. Abad, M. P. Kishi, A. Perales, New phenalenone456 type phytoalexins from Musa acuminata (colla AAA) grand nain, Nat. Prod. Lett. 6 (1995) 2345730.

458 (3) J. G. Luis, E. H. Lahlou, L. S. Andres, F. Echeveni, W. Q. Fletcher, Phenylphenalenonic 459 phytoanticipins. New acenaphtylene and dimeric phenylphenalenones from the resistant Musa 460 selected hybrid SH-348 1, Tetrahedron 53 (1997) 8249-8256.

461 (4) J. F. Hennen, J. W. McCain, A new working definition of the term "Phytoalexin", Plant 462 Disease 64 (1980) 734.

463 (5) J. P. Knox, A. D. Dodge, Singlet Oxygen and Plants, Phytochem. 24 (1985) 889-896.

464 (6) K. R. Downum, J. Wen, The Occurrence of Photosensitizers Among Higher Plants, ACS 465 Symp. Ser. 616 (1995) 135-143.

466 (7) K. R. Downum, S. Nemec, Light-Activated Antimicrobial Chemicals from Plants: Their 467 Potential Role in Resistance to Disease-Causing Organisms, Eds J. Heitz and K. R. Downum, 468 ACS Symp. Ser. 339 (1987) 28i.

469 (8) A. Lazzaro, M. Corominas, C. Marti, C. Flors, R. Izquierdo, T. A. Grillo, J. G. Luis, S. 470 Nonell, Light- and singlet oxygen mediated antifungal activity of phenylphenalenone 471 phytoalexins, Photochem. Photobiol. Sci. 3 (2004) 706-710.

472 (9) M. R. Berenbaum, R. A. Larson, Flux of singlet oxygen from leaves of phototoxic plants, 473 Experientia 44 (1988) 1030-1032. 
474 (10) C. S. Foote, Mechanistic Characterization of Photosensitized Reactions. In 475 Photosensitisation. Molecular, Cellular and Medical Aspects; Moreno, G., Pottier, R. H., 476 Truscott, T. G., Eds.; Springer-Verlag: Berlin, 1988.

477 (11) A. V. B. Sankaram, M. Marthandamurthi, Pygmacone, a phenalenone derivative of 478 diterpenoid origin from pygmacopremna herbacea, Phytochem. 30 (1991) 359-360.

479 (12) R. G. Cooke, J. M. Edwards, Naturally occurring phenalenones and related compounds. 480 Prog. Chem. Org. Nut. Prod. 40 (1981) 153-190.

481 (13) R. Schmidt, C. Tanielian, R. Dunsbach, C. Wolff, Phenalenone, a universal reference 482 compound for the determination of quantum yields of singlet oxygen $\mathrm{O}_{2}\left({ }^{\mathrm{l}} \Delta_{\mathrm{g}}\right)$ sensitization, $\mathrm{J}$. 483 Photochem. Photobiol. A 19 (1994) 11-17.

484 (14) E. Oliveros, P. Suardi-Murdseco, T. Aminian-Saghafi, A. M. Braun, H. J. Hansen, 1H485 Phenalen-1-one: photophysical properties and singlet-oxygen production, Helv. Chim. Acta 74 $486 \quad$ (1991) 79-90.

487 (15) S. Nonell, M. Gonzilez, F. R. Trull, 1H-Phenalen-l-one-2- sulfonic acid: an extremely 488 efficient singlet molecular oxygen sensitizer for aqueous media, Afinidad 50 (1993) 445-450.

489 (16) E. Oliveros, S. H. Bossmann, S. Nonell, C. Marti, G. Heit, G. Troscher, A. Neuner, C. 490 Martinez, A. M. Braun, Photochemistry of the singlet oxygen $\left[\mathrm{O}_{2}\left({ }^{\mathrm{d}} \Delta_{\mathrm{g}}\right)\right]$ sensitizer 491 perinaphthenone (phenalenone) in N,N'-dimethylacetamide and 1,4-dioxane, New J. Chem. 23 492 (1999) 85-93.

493 (17) G. P. Rabold, K. H. Bar-Eli, E. Reid, K. Weiss, Photochemically Generated Free Radicals. I. 494 The Perinaphthenone System, J. Chem. Phys. 42 (1965) 2438-2448.

495 (18) D. Post-Beittenmiller, Biochemistry and molecular biology of wax production in plants. 496 Annu. Rev. Plant Physiol. Plant Mol. Biol. 47 (1996) 405-430. 
(19) M. A. Jenks, H. A. Tuttle, S. D. Eigenbrode, K. A. Feldmann, Leaf epicuticular waxes of

498 the eceriferum mutants in Arabidopsis, Plant Physiol. 108 (1995) 369-77.

499 (20) A. ter Halle, D. Drncova, C. Richard, Phototransformation of the Herbicide Sulcotrione on

500 Maize Cuticular Wax, Environ. Sci. Technol. 40 (2006) 2989-2995.

501 (21) S. Monadjemi, M. El Roz, C. Richard, A. ter Halle, Photoreduction of Chlorothalonil

502 Fungicide on Plant Leaf Models, Environ. Sci. Technol. 45 (2011) 9582-9589.

503 (22) A. ter Halle, D. Lavieille, C. Richard, The effect of mixing two herbicides mesotrione and

504 nocosulfuron on their photochemical reactivity on cuticular wax film, Chemosphere 79 (2010)

$505 \quad 482-487$.

506 (23) C. Flors, C. Prat, R. Suau, F. Najera, S. Nonell, Photochemistry of phytoalexins containing 507 phenalenone-like chromophores: Photophysics and singlet oxygen photosensitizing properties of 508 the plant oxoaporphine alkaloid oxoglaucine. Photochem. Photobiol. 81 (2005) 120-124.

509 (24) C. Flors, S. Nonell, Light and singlet oxygen in plant defense against pathogens: Phototoxic 510 phenalenone phytoalexins, Acc. Chem. Res. 39 (2006) 293-300.

511 (25) S. Monadjemi, A. ter Halle, C. Richard, Reactivity of cycloxydim toward singlet oxygen in 512 solution and on wax film, Chemosphere 89 (2012) 269-273.

513 (26) M. L. Dell'Arciprete, L. Santos-Juanes, A. Arques, R.F. Vercher, A.M. Amat, J. P. 514 Furlong, D. O. Martire, M. C. Gonzalez, Reactivity of neonicotinoid pesticides with singlet 515 oxygen, Catal. Today 151 (2010) 137-142.

516 (27) S. E. Braslavsky, Glossary of Terms used in Photochemistry $3^{\text {rd }}$ Edition, Pure Appl. Chem., $517 \quad 79$ (2007) 293-465.

518 (28) F. Bonnichon, C. Richard, Phototransformation of 3-hydroxybenzonitrile in water. J. 519 Photochem. Photobiol. A 119 (1998) 25-32. 
520 (29) D. R. Worrall, , S. L. Williams, Diffuse-Reflectance Laser Flash Photolysis, Encyclopedia

521 of Modern Optics Volume 1, R. D. Guenther, D. G. Steel and L. Bayvel (eds), Elsevier, Oxford, 522 2004, pp. 31-38.

523 (30) F. Wilkinson, R. Beer, Diffuse reflectance laser photolysis of adsorbed molecules, in 524 Photochemical processes in organised molecular systems, K. Honda, Editor, 1991, Elsevier 525 Science, Amsterdam, pp. 377-398.

526 (31) W. J. Albery, P. N. Bartlett, C. P. Wilde, J. R. Darwent, A general model for dispersed 527 kinetics in heterogeneous systems, J. Am. Chem. Soc. 107 (1985) 1854-1858.

528 (32) D. R. Worrall, I. Kirkpatrick, S. L. Williams, Bimolecular processes on silica gel 529 surfaces: energetic factors in determining electron-transfer rates, Photochem. Photobiol. Sci. 3 $530 \quad$ (2004) 63-70.

531 (33) S. L. Williams, I. Kirkpatrick, D. R. Worrall, Electron transfer reactions in ternary 532 systems on silica gel surfaces: evidence for radical cation diffusion, Photochem. Photobiol. Sci. 9 533 (2010) 937-941.

534 (34) F. M. Cabrerizo, M. L. Dántola, G. Petroselli, A. L. Capparelli, A. H. Thomas, A. M. Braun, 535 C. Lorente, E. Oliveros, Reactivity of Conjugated and Unconjugated Pterins with Singlet Oxygen $536\left(\mathrm{O}_{2}\left({ }^{1} \Delta_{\mathrm{g}}\right)\right)$ : Physical Quenching and Chemical Reaction, Photochem. Photobiol. 83 (2007) 526537534.

538 (35) E. Oliveros, P. Suardi-Murasecco, A. M. Braun, H. -J. Hansen, Efficiency of Singlet 539 Oxygen Quenching by Carotenoids Measured by Near-Infrared Steady-State Luminescence. In 540 Methods in Enzymology, Carotenoids, ed. L. Parker, Academic Press, San Diego, 1992, pp. 420541429. 
542 (36) M. Ménager, M. Siampiringue, M. Sarakha, Photochemical behaviour of 543 phenylbenzoquinone at the surface of the clays: Kaolinite, bentonite and montmorillonite, $\mathrm{J}$. 544 Photochem. Photobiol., A: Chem. 208 (2009) 159-163.

545 (37) M. Ménager, M. Sarakha, Simulated Solar Light Phototransformation of Organophosphorus 546 Azinphos Methyl at the Surface of Clays and Goethite, Environ. Sci. Technol. 47 (2013) 765$547 \quad 772$.

548 (38) C. Flors, S. Nonell, On the Phosphorescence of 1H-Phenalen-1-One, Helv. Chim. Acta 84 $549 \quad$ (2001) 2533-2539.

550 (39) R. Battino, Solubility Data Series: Volume 7, Oxygen and Ozone. Pergamon, Oxford, 551 England, 1981, 519p.

552 (40) Y. Gao, A. M. Baca, B. Wang, P. R. Ogilby, Activation Barriers for Oxygen Diffusion in 553 Polystyrene and Polycarbonate Glasses: Effects of Low Molecular Weight Additives, 554 Macromolecules, 27 (1994) 7041-7048.

555 (41) C Flors, S. Nonell, Radical species derived from phenalenone: characterization and role of 556 upper excited states, J. Photochem. Photobiol., A: Chem. 163 (2004) 9-12.

557 (42) M. Segado, M. Reguero, Mechanism of the photochemical process of singlet oxygen 558 production by phenalenone, Phys. Chem. Chem. Phys. 13 (2011) 4138-4148. 
562 Figure 1. (a) UV-Vis absorption spectra of PN contained in paraffin wax films normalized to 1$563 \mathrm{~cm}$ thickness (solid line) and dissolved in $n$-heptane (dotted line) at $10^{-4} \mathrm{M}$. (b) UV-Vis diffuse

564 reflectance spectra of cellulose (dashed line), PN mixed with cellulose at a 1\% in weight

565 concentration (dotted line), and difference spectrum (solid line).

566 Figure 2. UV-Vis absorption spectra of PN at (1-5) $\times 10^{-4} \mathrm{M}$ before irradiation, and after

567 different time of irradiation at $366 \mathrm{~nm}$ (a) in $n$-heptane (1-mm thickness cell) and (b) in a

568 paraffin wax film (420 $\mu$ m thickness).

569 Figure 3. TOF MS ES+ spectrum of PN irradiated in deoxygenated $n$-heptane.

570 Figure 4. (a) Transient absorption spectrum of ${ }^{3} \mathrm{PN}^{*}$ in paraffin wax film obtained upon

571 excitation at $355 \mathrm{~nm}$. (b) Deactivation kinetics of ${ }^{3} \mathrm{PN} *$ adsorbed on silica gel under air (solid

572 line) and under primary vacuum (dotted line) obtained after a laser pulse irradiation at $355 \mathrm{~nm}$

573 and monitored at $500 \mathrm{~nm}$.

574 Figure 5. Singlet oxygen near infrared phosphorescence signal under continuous irradiation (at $575367 \mathrm{~nm}$ ) of a paraffin wax film containing PN at concentrations ranging between $10^{-4}$ and $10^{-3}$ 576 M.

577 Figure 6. EPR spectra of the hydroxyperinaphthenyl radical recorded during the irradiation of 578 PN (a) dissolved in deoxygenated $n$-heptane, and (b) in air equilibrated paraffin wax.

579 Figure 7. Kinetics of formation of the hydroxyperinaphthenyl radical (HPN*) under continuous 580 irradiation of paraffin waxes containing (a) PN, (b) PN and tembotrione, (c) PN and pyrethrum 581 extract (irradiation using a Xe-Hg arc lamp). Tembotrione and pyrethrum extract pesticide 582 structures. 
584

585 Figure 1a

586

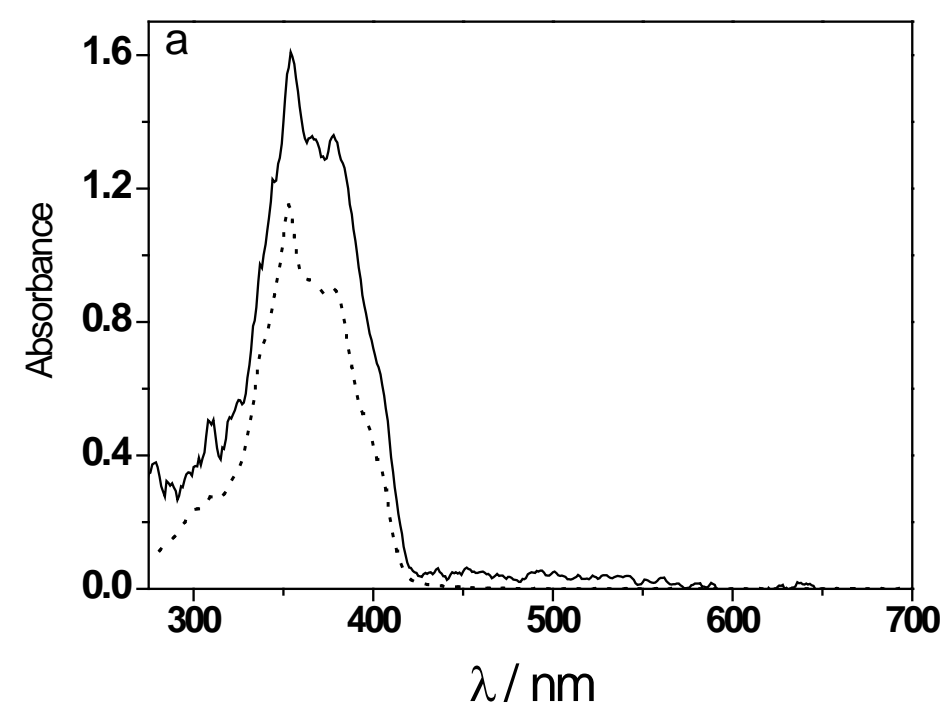

587

588 Figure 1b

589

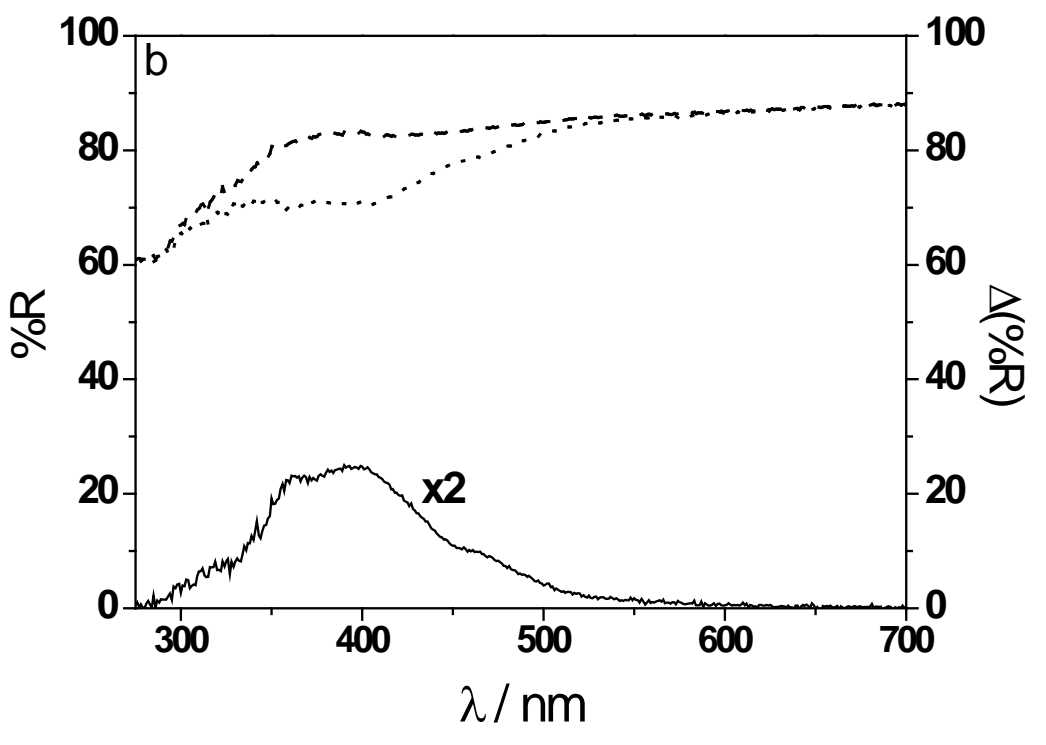

590 
Figure 2a

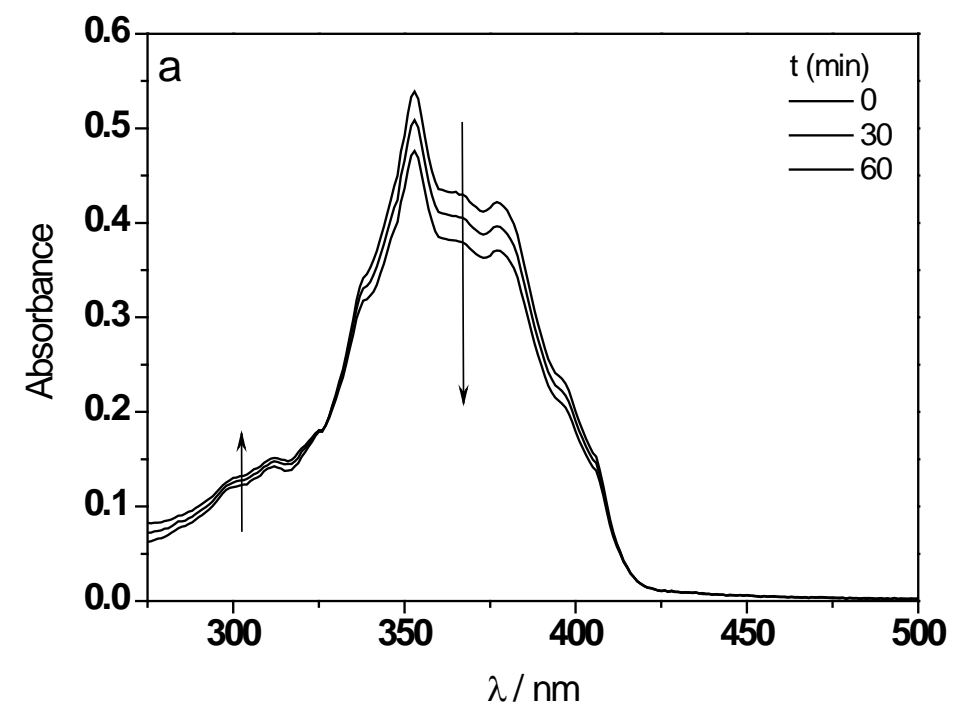

593

594

595 Figure 2b

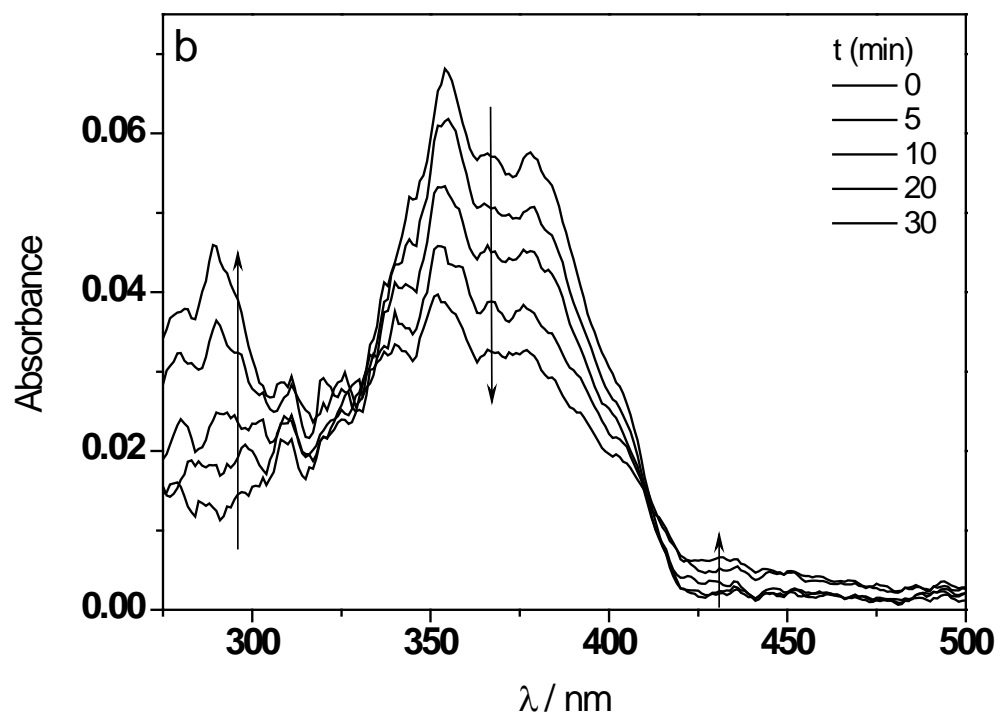

596

597

598 
600

601

602

603

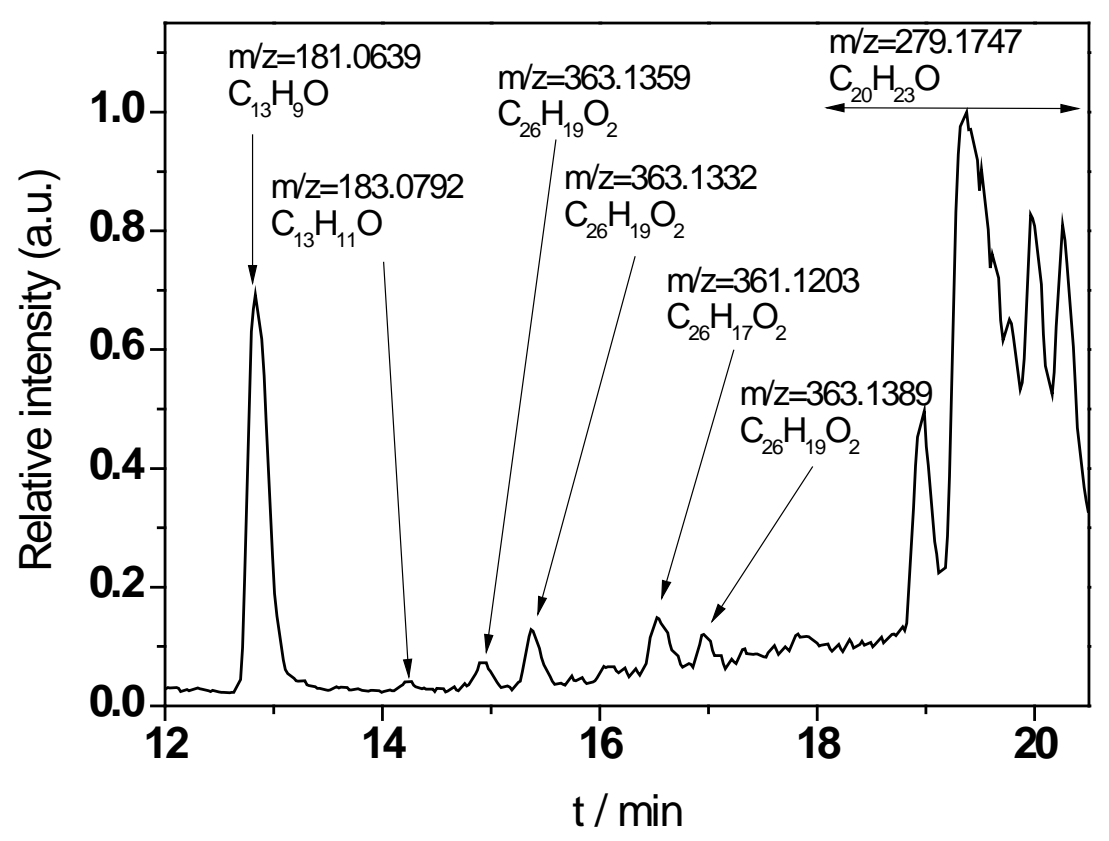

611

612

613

614

615 
616 Figure 4a

617

618

619

620

621

622

623

624

625

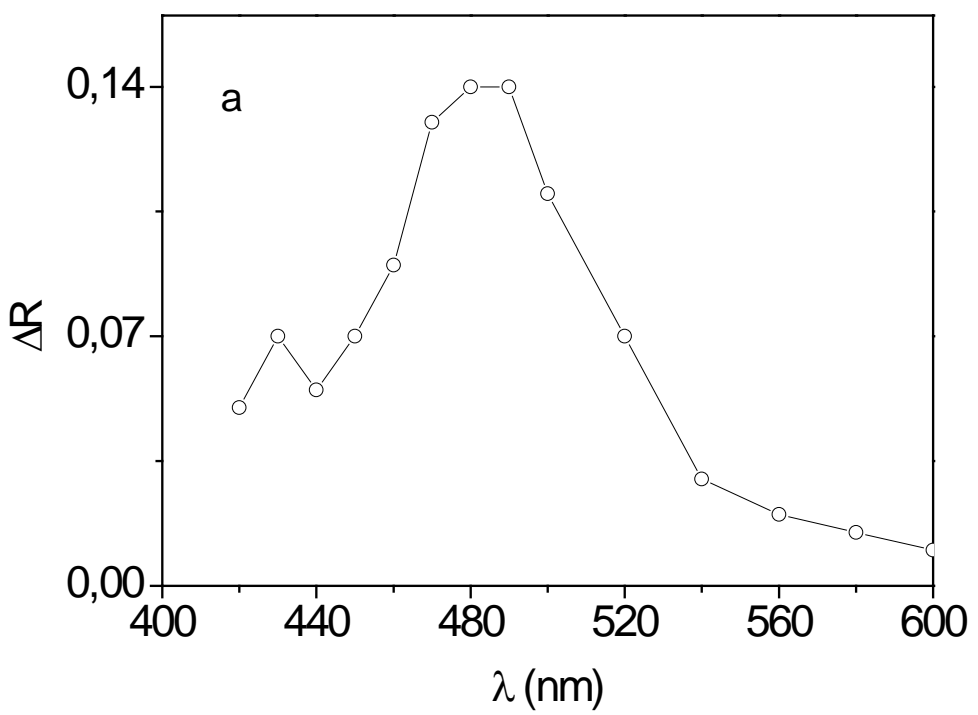

626

627 Figure 4b

628

629

630

631

632

633

634

635

636

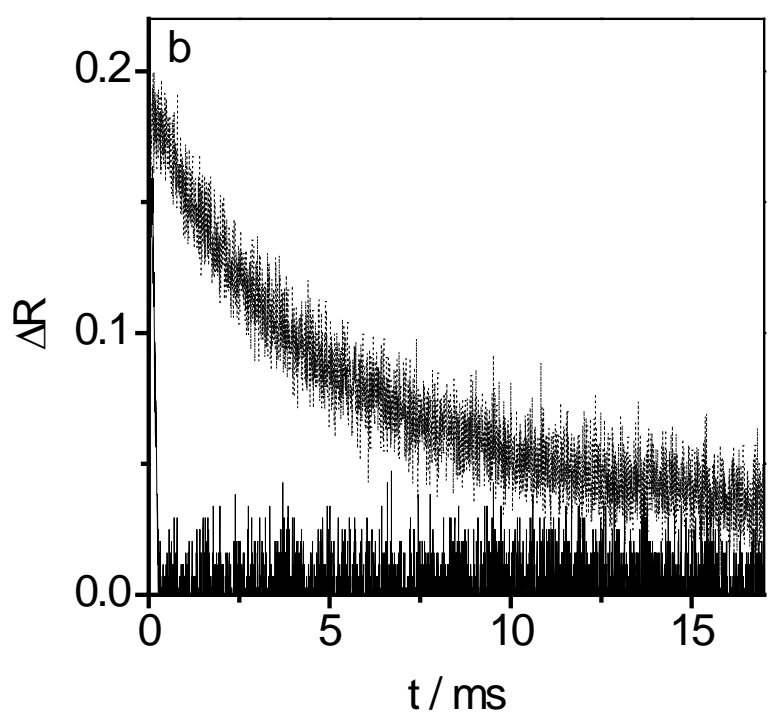

637 
638 Figure 5

639

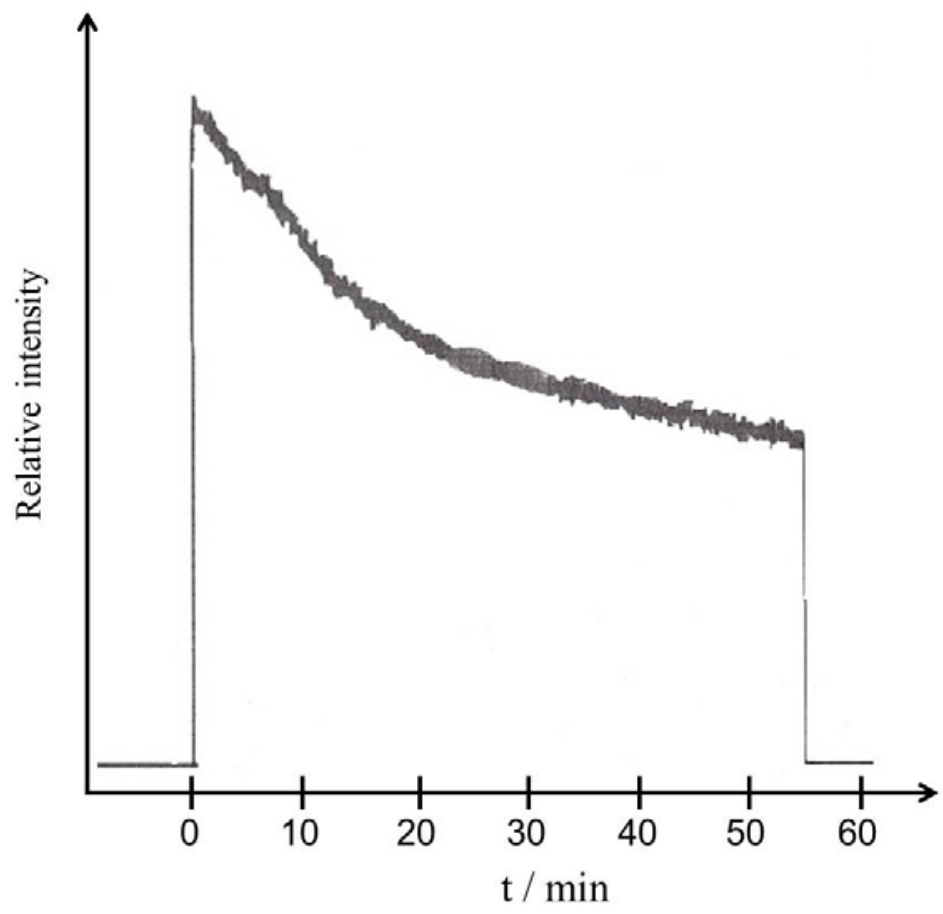

640

641

642 
643 Figure 6

644

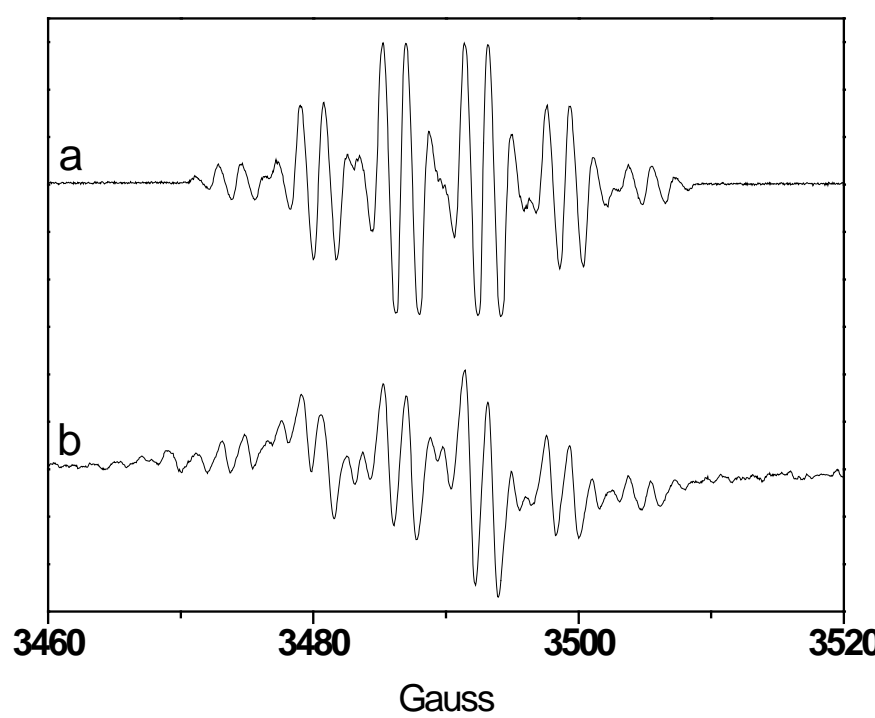<smiles></smiles>

645

646

647 
649
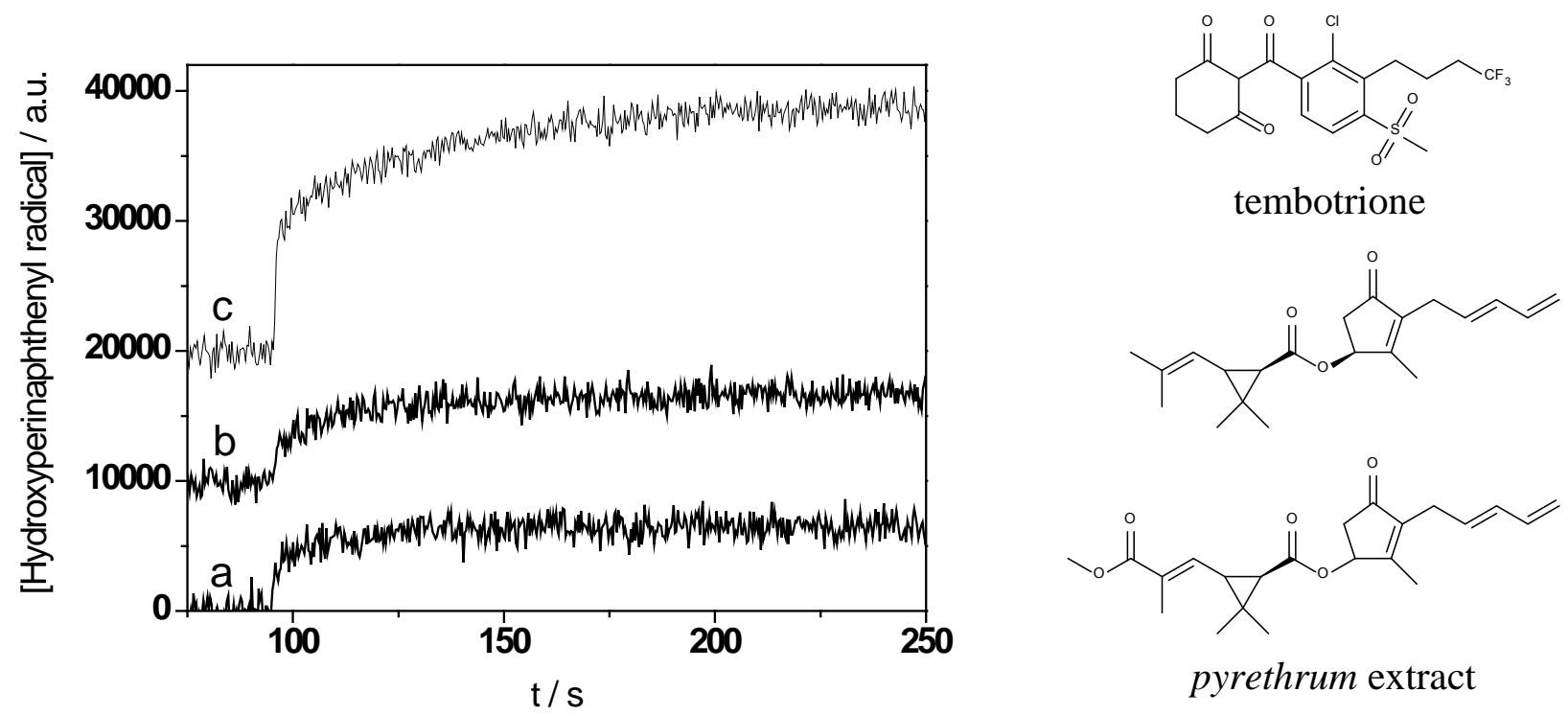

650

651 
653 Scheme 1. Chemical reactions induced by PN irradiation in paraffin wax.

654

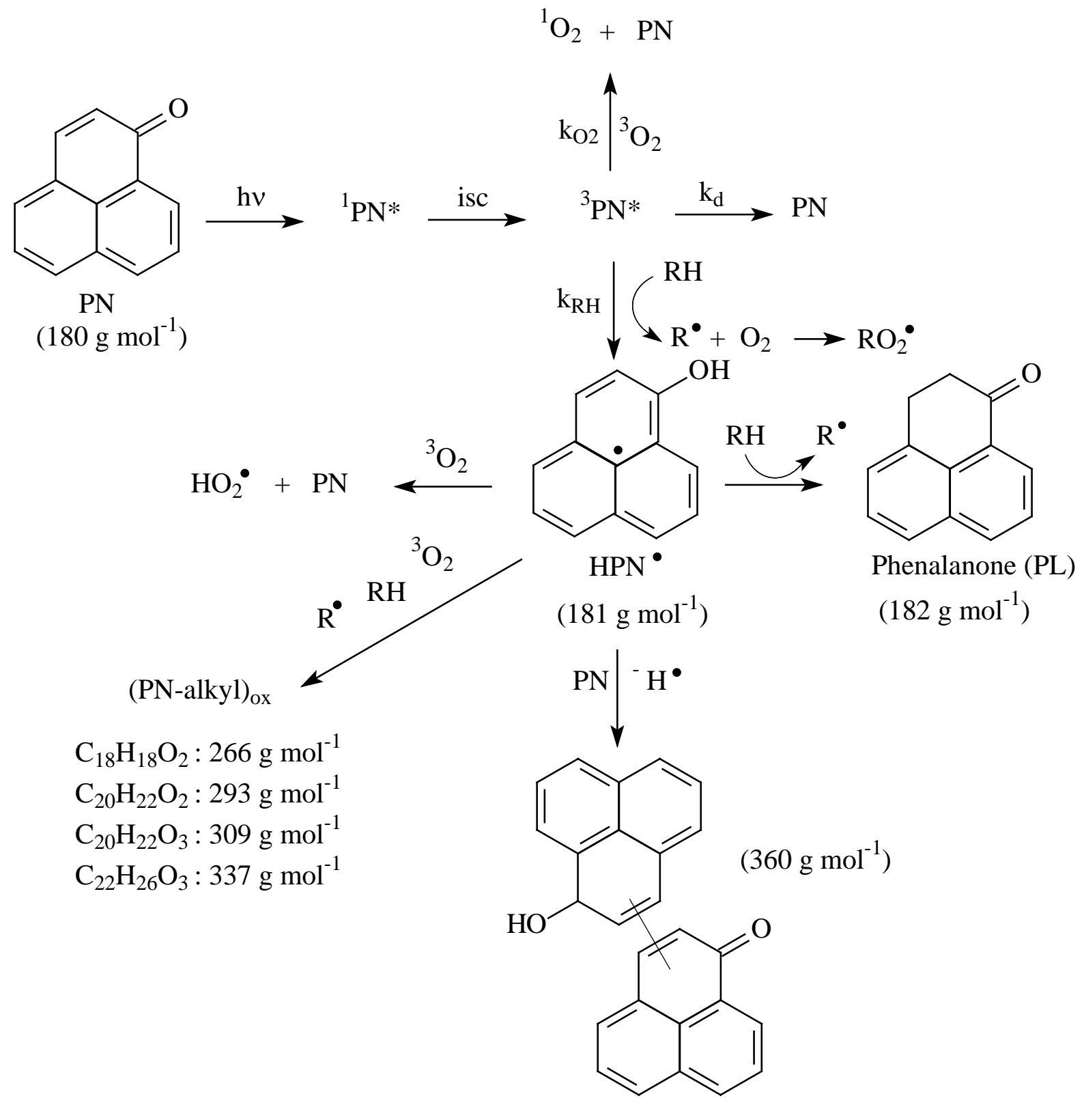

